\title{
Age-Linked Declines in Retrieving Orthographic Knowledge: Empirical, Practical, and Theoretical Implications
}

\author{
Donald G. MacKay and Lise Abrams \\ University of California, Los Angeles
}

\begin{abstract}
This study developed and tested a Transmission Deficit hypothesis of how aging affects retrieval of orthographic knowledge. Young, older, and very old adults heard a tape-recorded series of difficultto-spell words of high and low frequency, spoken slowly, clearly and repeatedly, and wrote down each word at their own pace. With perceptual errors and vocabulary differences factored out, misspellings increased with aging, especially for high-frequency words. In addition, data from a metamemory questionnaire indicated that the oldest adults were aware of their declining ability to spell. These findings were not due to general slowing, educational factors, hours per week spent reading, writing, or solving crossword puzzles, or age-linked declines in monitoring or detecting self-produced errors. However, the results fit Transmission Deficit predictions, and suggested an age-linked decline in retrieval of orthographic knowledge that resembles age-linked declines in spoken word retrieval observed in many other studies. Practical implications of this age-linked decline for conceptions of normal aging are noted.
\end{abstract}

Although many researchers have examined how aging affects the retrieval of phonology during spoken language production (e.g., Albert, Heller, \& Milberg, 1988; Au et al., 1995; Balota \& Duchek, 1988; Bowles, Obler, \& Poon, 1989; Bowles \& Poon, 1985; Burke, MacKay, Worthley, \& Wade, 1991; Cohen \& Faulkner, 1986; Liss, Weismer, \& Rosenbek, 1990; Maylor, 1990; McCrae, Arenberg, \& Costa, 1987; Mitchell, 1989; Nicholas, Barth, Obler, Au, \& Albert, 1997; Nicholas, Obler, Albert, \& Goodglass, 1985; Rastle \& Burke, 1996; Thomas, Fozard, \& Waugh, 1977), to our knowledge, no one has directly examined how aging affects the retrieval of orthography, the corresponding level of written language production. However, the effects of aging on the generation of letter strings, otherwise known as the ability to spell, are of interest on empirical, practical, and theoretical grounds. Empirically, age-linked declines in language production have been repeatedly demonstrated at phonological levels, and it is important to determine whether similar age-linked declines occur at orthographic levels. Practically, a demonstration of age-linked declines in spelling ability would help define the nature of normal aging and would support steps to evaluate and overcome the possible consequences of those declines. Theoretically, the effects of aging on the ability to

Donald G. MacKay and Lise Abrams, Department of Psychology, University of California, Los Angeles. Lise Abrams is now at the Department of Psychology, University of Florida.

This research was supported by National Institute for Aging Grant R01 AG 097705 and a National Science Foundation graduate fellowship to Lise Abrams. We thank Victor Hwang, Manissa Pedroza, and Meredith Shafto for assistance with the study and Deborah Burke and Lori James for helpful comments on a draft of this article.

Correspondence concerning this article should be addressed to Donald G. MacKay, Department of Psychology, University of California, Los Angeles, California 90095-1563. Electronic mail may be sent to mackay@psych.ucla.edu. spell may help distinguish between alternate accounts of agerelated declines in language production.

With such empirical, practical, and theoretical considerations in mind, we first review the data on how aging affects spoken word retrieval and then outline theoretical issues associated with the effects of aging on spoken language production. We next review general theories and empirical research on the representation of orthographic knowledge and develop a new theory that makes detailed predictions about the effects of aging on retrieval of orthographic knowledge. Finally, we discuss the variables and other procedural details adopted in our experiment for testing those predictions.

\section{Empirical Effects of Aging on Spoken Word Retrieval}

Older adults are slower and less accurate than young adults in saying a word that corresponds to a definition (e.g., Bowles \& Poon, 1985), starts with a specified letter, or falls into a specified category (e.g., McCrae et al., 1987). Older adults are also slower (Thomas et al., 1977) and less accurate than young adults at naming pictures of familiar objects and actions (e.g., Albert et al., 1988; An et al., 1995; Bowles et al., 1989; Mitchell, 1989; Nicholas et al., 1985, 1997; however, see Poon \& Fozard, 1978). Tip-of-the-tongue (TOT) phenomena, in which speakers can retrieve the meaning of a low-frequency word that they know they know, but cannot produce the word because they are unable to retrieve its full phonology, also increase with age, both in everyday life and in laboratory settings (Burke et al., 1991; Maylor, 1990; Rastle \& Burke, 1996). Finally, older adults produce words more slowly than young adults at maximum rate and take longer than young adults to begin to say a visually presented word (Balota \& Duchek, 1988; Liss et al., 1990).

Two aspects of this pattern of age-linked declines in spoken word retrieval are remarkable. One is that these declines do not reflect across-the-board declines in language processes because processing within the semantic system exhibits age constancy 
(see, e.g., MacKay \& Burke, 1990). The other is that these declines involve the retrieval of familiar information (so-called crystallized intelligence; Christensen, 1998) and cannot be explained in terms of well-known deficits in the ability to encode new information (so-called fluid intelligence; Christensen, 1998). If spelling retrieval exhibits similar declines in collegeeducated older adults, then this remarkable pattern would extend to the corresponding level of writing, another highly practiced language production skill.

However, we note at the outset that age-linked spelling deficits are unlikely: According to a review of research on semantic memory and aging (Bowles, 1993), age differences do not occur "in the ability to access the internal representation of a word in semantic memory when the stimulus provides the orthography or phonology of the target word" (p. 304). Because the stimulus provides the target phonology when people are asked to spell auditorily presented words, aging should not affect correct spelling if Bowles's account is correct. Aging should likewise have little effect on spelling under the still prevalent view that crystallized intelligence, particularly verbal skills, show little or no decline in old age (Botwinick, 1984, pp. 255-271; Christensen, 1998).

\section{Aging and Retrieval of Phonology: Theoretical Issues}

To date, theories of age-linked declines in spoken word retrieval have focused mainly on questions of locus: Are the declines attributable to one cognitive system more so than to others? For example, are age-linked declines in picture naming attributable to the system for perceiving the pictures, to the system for producing names, or to both? Furthermore, if the system for producing names is involved, are the declines attributable to the production of phonology, to the production of semantics, or to both? Thus, one account of age-linked declines on the Boston Naming Test (BNT) postulates age-linked "difficulties with perceptual and semantic processing' (Aul et al., 1995, p. 310). Another account interprets age-linked increments in the time to retrieve familiar words as having a "systemuniversal" cause (i.e., a general slowing factor that applies across all cognitive systems, not just perceptual or semantic systems or even language systems per se; see Burke \& MacKay, 1997, for a recent review). A third account, the Transmission Deficit hypothesis (TDH) of MacKay and Burke (1990), can be considered a hybrid account with both system-specific and system-universal aspects: The TDH postulates a universal factor, age-linked deficits in the transmission of priming across connections between nodes in a highly interconnected network, but the effects of transmission deficits vary depending on the detailed structure of the connections involved. According to this theory, connections differ in structure for perceptual versus production systems and for phonological versus semantic units within the production system, so that age-linked declines on the BNT and on other language production tasks are mainly attributable to production rather than perceptual systems and are mainly attributable to producing phonological rather than semantic units under the TDH. Because the TDH also predicts effects of aging on written language production that parallel those for spoken language production, we examine the mechanisms of this theory in detail, first for spoken language production and then for written language production.

\section{The TDH and Retrieval of Phonology}

Under the TDH, connections between nodes, the hypothetical processing units in the Node Structure theory (NST) of MacKay (1987), transmit priming less efficiently as a function of three factors: aging, nonrecent activation of the connected nodes, and infrequent activation over the course of a lifetime. Priming can be inhibitory or excitatory in nature and is transmitted simultaneously or in parallel across all active connections. Priming has two main functions. One is to allow the simultaneous integration of many different sources of information. The other is to prepare nodes for possible activation: Only the most primed node of a given type can be activated at any given point in time. Unlike priming, then, activation requires the engagement of a special activating mechanism that follows a "most-primed-wins" activation principle. Also unlike priming, activation proceeds sequentially so that the units represented by nodes can be retrieved in proper order as well as at the proper time in speech, writing, typing, and spelling.

Nodes for producing spoken speech in NST are organized hierarchically into three systems: a general-purpose semantic system representing the meanings of words, a phonological system representing syllables and segments or speech sounds, and a muscle movement system for moving (e.g., the jaw, tongue, and laryngeal structures for spoken speech). To illustrate this hierarchical organization, Figure 1 shows some of the connections that play a role in producing the word calendar at the semantic and phonological levels. The highest level, the lexical node representing calendar in the semantic system, is connected top-down to three nodes representing the syllables $/ \mathrm{ka} /$ and /len/ and /dêr/ in the phonological system in Figure 1. ${ }^{1}$ Syllable nodes are hierarchically connected top-down to nodes representing phonological compounds (e.g., /-en/ and /-êr/) and segments (e.g., /k-/), which map onto a hierarchically organized system of muscle movement nodes for spoken production of the word calendar. (See MacKay, 1987, pp. 36-38, for details of node structures within the phonological and muscle movement systems.) In error-free spoken production of the word calendar, then, the lexical node for calendar is activated first, followed by its first syllable node and the first segment node of its first syllable, before the muscle movement nodes for producing that initial segment can be activated and the onset of movement can begin.

How do the hierarchical, top-down connections in Figure 1 bear on the TDH? Effects of a transmission deficit in the theory are likely to be greatest when a node critical to a task is rarely and nonrecently activated and receives priming from only a single source or connection within the network. The basis for this "single-source condition"' is that no other sources of priming will be able to offset the reduced priming across a critical connection receiving priming from a single source. This is pre-

\footnotetext{
${ }^{1}$ To distinguish phonological from orthographic units, we place phonological units between slashes, (e.g., /-êr/) and orthographic units between brackets (e.g., [-ER]), a generally accepted convention.
} 


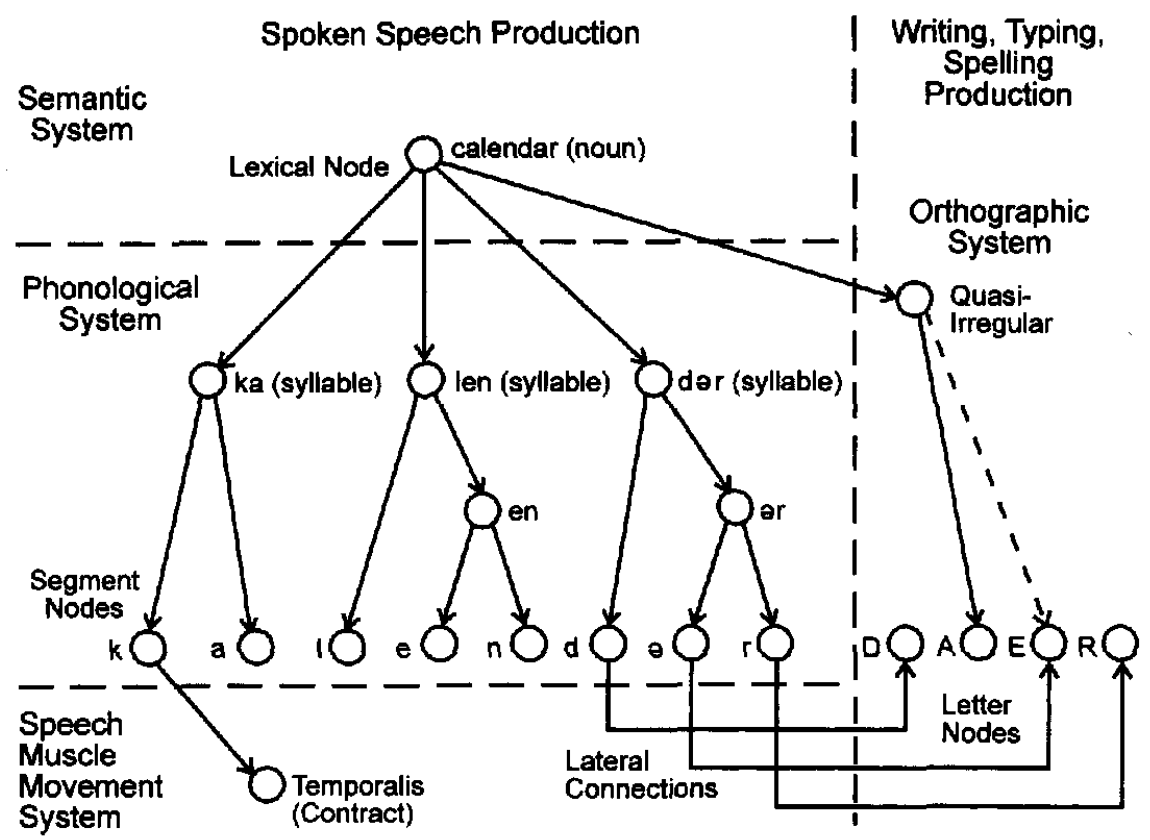

Figure 1. A sample of top-down and lateral connections in Node Structure theory for producing the word calendar at the semantic, phonological, and orthographic levels. The broken top-down link indicates an inhibitory connection, and the solid top-down links indicate excitatory connections. Nodes within the muscle movement systems for spoken speech, handwritten spelling, and typed spelling have been omitted.

cisely the case for priming delivered top-down to phonological nodes during spoken language production: Phonological nodes have only a single or critical top-down connection and so receive a single source of priming without the possibility of convergence or summation of priming from other nodes to offset age-linked transmission deficits. For example, the node representing the syllable $/ \mathrm{ka} /$ in Figure 1 receives top-down priming from a single lexical node during spoken production of the word calendar. This limitation in how many connections can deliver topdown priming to phonological nodes during spoken language explains why phonological but not semantic information is inaccessible in TOTs. The single-source condition does not in general hold for units in the semantic system, where connections generally converge from many nodes onto one node. Consequently, many sources of priming can offset age-linked transmission deficits across any one connection between semantic units, unlike phonological units (see MacKay \& Burke, 1990; also see MacKay, Abrams, \& Pedroza, in press). The single-source condition also explains why TOTs increase with aging and why older adults in the TOT state take longer to resolve TOTs, access less phonological information about the target word, have fewer alternative words come persistently to mind, and experience disproportionately more TOTs for proper names than do young adults (see Burke et al., 1991). The susceptibility of top-down phonological priming to transmission deficits also explains other age-linked difficulties in spoken word retrieval. For example, age differences in word retrieval decrease when orthographic and phonological cues are provided, but not when additional semantic cues are provided (Bowles \& Poon, 1985), as if the age-linked declines affect retrieval of phonology more so than semantics. (For detailed TDH accounts of these and a wide range of other aging effects, see MacKay \& Burke, 1990.)

\section{Aging and Retrieval of Orthography: Research and Theory}

Although many sophisticated empirical studies have examined orthographic processes "on the input side," especially the time required to read visually presented words aloud (see, e.g., Glushko, 1979; Jared, McRae, \& Seidenberg, 1990), empirical research on spelling retrieval in educated adults is extremely limited, consisting largely of single case studies of spelling impairments in patients with brain damage (Badecker, Hillis, \& Caramazza, 1990; Caramazza \& Hillis, 1990; Hillis \& Caramazza, 1990; Katz, 1991; Levine, Mani, \& Calvanio, 1988; Neils, Boller, Gerdeman, \& Cole, 1989; Posteraro, Zinelli, \& Mazzucchi, 1988). We found only two empirical studies on spelling retrieval in normal young adults (Fisher, Shankweiler, \& Liberman, 1985; Wing \& Baddeley, 1980) and no studies on spelling retrieval in healthy older adults.

Turning to theories, two contrasting classes of theories have been developed to explain the input-side orthographic processes that occur when normal young adults read a word aloud, but neither class of theories is currently capable of explaining all available data, even within this limited empirical range (see, e.g., Cortese \& Simpson, 1996; Rastle \& Coltheart, 1996). One class, known as parallel distributed processing (PDP) theories, represents orthographic knowledge in terms of connection strengths or weights within a complex, highly interactive network involving large numbers of excitatory and inhibitory connections for each 
word, without rules of any kind for representing either regularly or irregulariy spelled words (see, e.g., Plaut, McClelland, Seidenberg, \& Patterson, 1996). However, PDP theories of this type have had limited success in modeling the acquisition of spelling: Unlike humans, after more than 60 training trials with each of 1,000 words (preselected to exclude homophones and words with phonemes not in one-to-one correspondence with letters), the PDP program of Olson and Caramazza (1994) could at best spell only $70 \%$ of the words correctly.

The second class of input-side theories has been labeled "the orthodox theoretical conception of the processes subserving spelling in English" (Barry, 1994, p. 33). These "dual-route" theories (e.g., Coltheart, Curtis, Atkins, \& Haller, 1993) pastulate a categorical distinction between regularly versus irregularly spelled words, such that a word is regularly spelled if all of its speech sounds follow the most common orthography-topronunciation pattern in the lexicon but is irregularly spelled if it follows a unique or uncommon orthography-to-pronunciation pattern. For example, bunt, punt, and hunt are regularly spelled in dual-route theories because they follow the dominant orthography-to-pronunciation pattern in English, whereas bush and push are irregularly spelled because they follow an uncommon orthography-to-pronunciation pattern.

In dual-route theories, an "indirect" ' route from orthographyto-phonology-to-semantics incorporates grapheme-to-phoneme correspondence rules for translating orthography into phonology and plays an essential role in pronouncing regularly spelled words such as hunt. However, in the case of irregularly spelled words such as bush, a "direct route" leads straight from orthography to semantics, bypassing phonology and the grapheme-tophoneme correspondence rules. This direct route directly accesses the meaning of irregularly spelled words, which in turn enables the speaker to pronounce these words.

In contrast to the many input-side theories devoted to the task of reading visually presented words aloud, there are no detailed output-side theories to explain how normal adults spell words letter by letter in self-generated typing, writing, or spoken spelling production or in the task examined here, manually transcribing auditorily presented words. Detailed theories of how aging affects retrieval of orthographic knowledge are also nonexistent. Moreover, creating an output-side theory by "mirror imaging" an input-side theory of orthographic processing is impossible because instances of "regularity" differ on the input- versus the output-side: In general, input-side (orthography-to-phonology) relations are more regular or consistent than output-side (phonology-to-orthography) relations (see Barry, 1994). For example, STREET has only one possible pronunciation and is regular on the input side (the orthography-to-phonology direction), but STREET is irregular on the output side (the phonology-to-orthography direction) because /striyt/ could be spelled STREAT. We therefore had to develop an output-side theory of our own to guide our research on the effects of aging on the ability to spell auditorily presented words. The theory is a natural extension to orthographic retrieval of the TDH of MacKay and Burke (1990) and the NST account of phonological retrieval discussed earlier.

\section{NST and the Retrieval of Orthography}

Our first assumption is that "regular spelling" is a valid concept but that it applies to "speech sounds in context": That is, we define a speech sound as regularly spelled if it follows the most common spelling pattern for that speech sound in that context for all words of that type in the lexicon, and we define a speech sound as irregularly spelled if it follows a unique or uncommon spelling pattern. For example, the speech sound $/ \hat{\mathrm{e}} /$ in cooker is regularly spelled because most nouns of that type (e.g., worker, baker, maker) follow the same spelling pattern, but $/ \hat{\mathrm{e}} /$ is irregularly spelled in calendar because only a few other nouns (e.g., beggar, burglar) spell /-êr/ as [-AR]. However, only one speech sound in calendar is irregularly spelled under NST. Its remaining seven speech sounds are regularly spelled. This contrasts with dual-route theories, in which words are the unit of analysis and calendar is simply an irregularly spelled word.

To further illustrate the concept of "speech sounds in context" in NST, the speech sound / $/$ Š/ is usually spelled $\mathrm{CH}$ in initial positions (e.g., CHIP, CHURN; excluding non-English words such as Tschaikovsky) and after a complex vowel (e.g., BIRCH, BLEACH; MacKay, 1987, p. 32). However, $/ \mathrm{t} \check{S} /$ is usually spelled $\mathrm{TCH}$ when it follows immediately after a short vowel as in CATCH and SCOTCH. A similar concept of "orthographic units in context" is necessary to represent "purely orthographic regularities" such as the rule [I] before [E] except after [C]; to represent relations between orthographic units (as in doublets such as [-MM-] and [-SS-] and digraphs such as - $\mathrm{CK}, \mathrm{SH}-$, and $\mathrm{CH}-$ ); and to represent relations between orthographic units, morphological units, and different types of phonological units (e.g., consonants, consonant clusters, vowels, and vowel groups or rimes; see Treiman, 1993, pp. 279-280; also see Olson \& Caramazza, 1994).

Like phonological nodes, orthographic nodes are part of a hierarchically organized network that originates in the generalpurpose semantic system. The lexical node for a word is connected top-down to nodes in the orthographic system, which are connected top-down to nodes in the muscle movement systems for writing and typing. However, writing and typing are special because the orthographic system also receives nonhierarchic or lateral connections from the phonological system that determine the spelling for "regularly spelled" letters in a word and enable writers to generate a "regular spelling" for words that they have heard but never previously seen spelled. ${ }^{2}$

For spelling an irregularly spelled component of a word, the orthographic system contains a "quasi-irregular node" that introduces the irregularly spelled letters and blocks the regular spelling pattern. By way of illustration, Figure 1 shows the quasi-irregular node and lateral connections for spelling the word calendar under NST. The highest level, lexical node representing calendar connects top-down to a node in the orthographic system that represents the fact that calendar belongs to a subset of quasi-irregular nouns that spell /ê/ as [A]. This quasi-irregular node is connected top-down via an inhibitory

\footnotetext{
${ }^{2}$ For regularly spelled words, the orthographic system also projects lateral connections to the phonological system that enable people to read visually never previously encountered words aloud. These lateral orthography-to-phonology connections are controversial in detail (compare, e.g., Coltheart, Curtis, Atkins, \& Haller, 1993, with Plaut, McClelland, Seidenberg, \& Patterson, 1996), irrelevant to the present task, and discussed no further here.
} 
connection to the letter $[\mathrm{E}]$ and via an excitatory connection to the letter $[\mathrm{A}]$.

We turn now to the orthographic processes in NST for writing or typing irregularly spelled letters in auditorily presented words. These NST processes are general in nature, identical to those for phonology discussed earlier, and independent of the validity of the representational assumptions embodied in Figure 1. Under NST, complex priming interactions between the lexical node for the word, its phonological nodes, and its quasi-irregular node enable activation of the appropriate orthographic nodes for writing and typing irregularly spelled letters and letter clusters. For example, when writing the word calendar, the lexical node for calendar is activated first, which causes strong topdown priming of the phonological nodes for calendar and its quasi-irregular node in the orthographic system (see Figure 1). Activating this quasi-irregular node in turn delivers strong excitatory priming to the letter [A] and strong inhibitory priming to the letter [E], which counteracts the priming arriving from the lateral connections from the phonological system, prevents activation of the regular spelling pattern, and enables correct spelling of calendar as calendar (see Figure 1). This same quasi-irregular node also becomes activated when writing, typing, or spelling the small number of other nouns that spell /ê/ as [A] (e.g., burglar, beggar), ergo the term quasi-irregular.

To summarize, the structure of orthographic knowledge in NST resembles dual-route theories in some abstract respects because quasi-irregular nodes represent a type of orthographic rule, and the top-down and lateral connections in NST can be viewed as multiple "routes," albeit simultaneous and "cooperative" routes rather than "either-or" routes. However, NST also differs from dual-route theories (e.g., Coltheart et al., 1993) in other respects (e.g., its rules are quasi-irregular rather than categorically irregular, unlike the phoneme correspondence rules in dual-route theories). At the same time, NST resembles PDP theories (e.g., Plaut et al., 1996) in some abstract respects (e.g., connection strengths or weights are a major factor in NST) but differs from PDP theories in other respects (e.g., connection weights are not the only factor in NST); how connections are structured is an equally important factor that enables representation of quasi-irregular rules.

\section{Effects of Aging on Orthographic Retrieval in NST}

We now examine the effects of age-linked transmission deficits on orthographic retrieval in NST. Transmission deficits in connections resembling those in Figure 1 predict that older adults will be especially likely to misspell irregularly spelled aspects of English words because nodes critical to this task satisfy the single source condition: They receive priming from only a single source or connection within the network. For example, the quasi-irregular node for calendar in Figure 1 can receive top-down priming only from its one connection with the lexical node for calendar. Consequently, deficits in transmission of priming across that one connection will reduce the likelihood of activating that quasi-irregular node. This can have two possible consequences. One is that the wrong quasi-irregular node becomes activated. Because only the most primed quasi-irregular node can be activated at any point in time, the wrong quasiirregular node may be activated in error if a transmission deficit prevents the appropriate quasi-irregular node from achieving most primed status. In short, older adults will sometimes apply the wrong quasi-irregular pattern when misspelling irregularly spelled words.

The second possible consequence is that no quasi-irregular node achieves enough priming to become activated, and the regular spelling pattern predominates. For example, if no quasiirregular node is activated in spelling the word calendar, the letter [E] will not be inhibited and the letter [A] will not be activated, and calendar will be misspelled calender, following the pattern represented by the lateral connections for spelling most English words. This possibility suggests that in absolute numbers, the misspellings of older adults will tend to have the same pronunciation as the original word under the TDH.

NST also predicts that misspellings attributable to age-linked transmission deficits will be less likely in absolute numbers for the regularly than irregularly spelled aspects of words. The lateral, phonology-to-orthography connections for spelling regularly spelled letters are used with extremely high frequency over the course of a lifetime, a factor that will tend to offset transmission deficits. By comparison, irregularly spelled components receive relatively little practice because they occur in only a few words, and these words generally contain more regularly than irregularly spelled components, as the calendar example illustrates. Thus, the lateral connection for spelling $/ r /$ as [R] may be activated many times a day when typing, writing, or spelling the many English words that contain one or more regularly spelled $/ \mathrm{r} / \mathrm{s}$. By contrast, the single connection linking calendar to its quasi-irregular node is unique to the word calendar (see Figure 1) and transmits priming only when writing, typing, or spelling the word calendar. Similarly, the single connection linking this quasi-irregular node to [A] (see Figure 1) is activated only when writing, typing, or spelling the small number of words that spell /ê/ as [A] (e.g., burglar, beggar). Moreover, age will multiply the frequency difference between regularly versus irregularly spelled letters. Over the longer lifetimes of older adults, nodes for regularly spelled letters will be activated much more often than nodes for irregularly spelled letters. Because this age-linked difference in frequency of activation will tend to offset age-linked transmission deficits, the TDH predicts that older adults will exhibit little or no deficit in spelling regularly spelled letters.

Nonetheless, the lateral connections that link phonological nodes to the orthographic nodes for representing regular spelling constitute a single source of priming that should eventually succumb to age-linked transmission deficits under the TDH (see Figure 1), so that very old adults should exhibit a deficit in spelling regularly as well as irregularly spelled aspects of words. However, transmission deficits in lateral connections can also exhibit paradoxical effects under NST. For example, a deficit in transmission of priming across the connection from to $/$-êf to [E] in Figure 1 will reduce the priming delivered to the letter [E], but this will increase the probability that calendar will be correctly spelled as calendar rather than misspelled as calender.

To summarize, NST makes many predictions that are counterintuitive within the context of current research (see Bowles, 1993; Christensen, 1998). Age-linked transmission deficits predict that misspellings will increase as a function of aging and that older adults will be especially likely to make errors on 
irregularly than regularly spelled parts of a word because age will multiply the frequency differences between irregularly and regularly spelled components. Similarly, the misspellings of older adults involving irregularly spelled components will in general be especially likely to have the same pronunciation as the original word because age will multiply the frequency differences between same- and different-pronunciation components. However, very old adults will also exhibit an age-linked increase in the absolute number of errors on regularly spelled parts of a word under NST.

NST also predicts that more low- than high-frequency words will be misspelled by both young and older adults because word frequency covaries with the recency and frequency of node activation, two factors that offset Iransmission deficits ( see, e.g., Burke et al., 1991). However, errors on both high- and lowfrequency words will tend to involve irregularly spelled letters more often than regularly spelled letters because of the different frequencies of these components. Moreover, for both young and older adults, misspellings of irregularly and regularly spelled letters will in general have the same pronunciation as the original word due to the greater frequency of same-pronunciation components.

To test these predictions, we presented a tape-recorded series of difficult-to-spell English words to young and older participants, who simply wrote the words down at their own pace, with instructions that encouraged accurate spelling. The instructions also deemphasized response speed to rule out possible explanations based on general slowing and age-linked interactions between speed and accuracy (see, e.g., Balota \& Ferraro, 1993). In addition, the words were repeated and articulated clearly at a relatively slow rate; participants could stop and restart the tape recorder as often as desired if they needed more time; and perceptual errors were factored out in our analyses to rule out age-linked sensory or perceptual deficits as determinants of our results. To test the prediction that low-frequency words would be misspelled more often than high-frequency words, half of our stimuli were high frequency (e.g., rhythm, spontaneous) and half were low frequency (e.g., chauffeur, pageant).

\section{Method}

\section{Participants}

The 85 participants fell into three groups, young, older, and oldest adults, with means and standard deviations for standard background characteristics shown in Table 1 . The 35 young adults (15 men and 20 women) were 17-23 years old and participated in return for partial course credit from introductory University of California, Los Angeles (UCLA), psychology classes. The 25 older adults ( 10 men and 15 women) were $60-71$ years old, and the 25 oldest adults ( 9 men and 16 women) were 73-88 years old. Older and oldest adults lived at their homes in greater Los Angeles, received $\$ 10$ plus travel expenses as members of the UCLA Cognition and Aging Lab pool (current sample size $=198$ ) and were recruited from the UCLA alumni association, senior citizen centers, and churches. All participants were native speakers of English and reported normal hearing, with no neurological or serious medical problems. The three groups differed reliably in years of education, $F(2,81)=31.68, p<.0001$, and Nelson-Denny Vocabulary Scale scores, $F(2,79)=26.25, p<.0001$. The older adults had more education and higher Nelson-Denny scores than the oldest adults, who had more education and higher Nelson-Denny scores than the young adults (see Table 1; all post hoc differences were significant at the .05 level per Bonferroni tests).

\section{Materials}

Materials consisted of the 40 words shown in Table 2, plus 6 practice words of comparable length, frequency, and spelling difficulty. All were listed as difficult to spell by Baron, Treiman, Wilf, and Kellman (1980) or by Norback (1974), and none were recognizably foreign (e.g., Tschai$k o v s k y$ ). Most were common nouns $(n=21)$, with some adjectives ( $n$ $=10)$, some verbs $(n=4)$, and at least one noun-verb (endeavor). Based on Francis and Kucera (1982; see Table 2), 20 experimental words were high frequency ( $M=31.3$ per million; e.g., committee $)$ and 20 were low frequency ( $M=2.2$ per million; e.g., inoculate). Highand low-frequency words were equally long (median length $=$ nine letters) and equally often ended in familiar suffixes (e.g., -ment, -er). A male experimenter recorded the words slowly and distinctly in standard American dialect on a Tascam Porta eight-track tape deck linked to Realistic Nova 55 headphones. The order of the words on the tape was randomized across five different versions of the experiment, with versions assigned to participants in each group by order of arrival.

Table 1

Background Characteristics and Questionnaire Responses for the Three Age Groups

\begin{tabular}{|c|c|c|c|c|c|c|}
\hline \multirow[b]{2}{*}{ Variable } & \multicolumn{2}{|c|}{ Young adults } & \multicolumn{2}{|c|}{ Older adults } & \multicolumn{2}{|c|}{ Oldest adults } \\
\hline & $M$ & $S D$ & $M$ & $S D$ & $M$ & $S D$ \\
\hline Age (years)* & 19.00 & 1.55 & 67.20 & 3.01 & 77.04 & 4.47 \\
\hline Education (years)* & 13.07 & 1.45 & 17.32 & 3.00 & 15.33 & 1.55 \\
\hline Health rating & 7.80 & 1.64 & 8.28 & 1.49 & 7.90 & 1.88 \\
\hline Nelson-Denny Vocabulary* & 15.29 & 2.98 & 21.12 & 2.47 & 19.43 & 4.08 \\
\hline Digit recall: Forward & 7.59 & 0.95 & 7.12 & 1.51 & 6.83 & 1.27 \\
\hline Digit recall: Backward & 5.34 & 1.29 & 5.20 & 1.22 & 4.83 & 1.47 \\
\hline Rated spelling ability at age 20 & & & 3.35 & 1.27 & 3.42 & 0.81 \\
\hline Rated spelling at current age & 3.67 & 0.78 & 3.47 & 1.42 & 3.86 & 1.05 \\
\hline Reading (hr/week) & 4.50 & 2.81 & 3.33 & 1.88 & 3.14 & 1.10 \\
\hline Writing (hr/week)* & 3.75 & 2.60 & 1.67 & 1.72 & 1.00 & 0.55 \\
\hline Crossword puzzles (hr/week) & 0.25 & 0.45 & 0.60 & 0.74 & 0.21 & 0.58 \\
\hline Rigor of spelling training & 7.17 & 1.11 & 6.00 & 3.40 & 5.38 & 2.10 \\
\hline
\end{tabular}

* Differences between age groups significant at the .001 level or less. 
Table 2

Frequency (per Million) of High-Versus Low-Frequency Stimuli (Ordered by Length)

\begin{tabular}{|c|c|c|c|}
\hline \multicolumn{2}{|c|}{ High-frequency stimuli } & \multicolumn{2}{|c|}{ Low-frequency stimuli } \\
\hline Word & Frequency & Word & Frequency \\
\hline FIERY & 7 & RAISIN & 1 \\
\hline RECIPE & 8 & INDICT & 2 \\
\hline GADGET & 11 & ERRATIC & 3 \\
\hline RHYTHM & 35 & ADJOURN & 4 \\
\hline BANQUET & 9 & PLUMBER & 4 \\
\hline PAGEANT & 12 & BROCCOLI & 1 \\
\hline DILEMMA & 27 & JEOPARDY & 4 \\
\hline ENDEAVOR & 5 & NINETIETH & 1 \\
\hline OCCASION & 80 & ACOUITTED & 2 \\
\hline GRIEVANCE & 6 & AFFIDAVIT & 2 \\
\hline RESERVOIR & 13 & INOCULATE & 3 \\
\hline CONSCIOUS & 46 & PNEUMONIA & 3 \\
\hline COMMITTEE & 188 & IRIDESCENT & 0 \\
\hline DESCENDANT & 7 & OBSEOUIOUS & 2 \\
\hline PICNICKING & 16 & ACRIMONIOUS & 0 \\
\hline ASSESSMENT & 30 & COUNTERFEIT & 1 \\
\hline OCCURRENCE & 40 & CONVALESCENT & 1 \\
\hline RESTAURANT & 53 & CALISTHENICS & 4 \\
\hline UNNECESSARY & 16 & PARAPHERNALIA & 1 \\
\hline SPONTANEOUS & 17 & INFINITESIMAL & 3 \\
\hline$M$ & 31.3 & $M$ & 2.2 \\
\hline
\end{tabular}

\section{Procedure}

All participants first answered a metamemory questionnaire concerning their spelling ability and activities with possible relations to spelling. The questionnaire asked how many hours per week participants spent reading, writing, and solving crossword puzzles; it also asked participants to rate how rigorously their grade school taught spelling skills on a 10-point scale $(1=\operatorname{lax}, 10=$ rigorous $)$ and to rate their current spelling ability on a 5 -point scale $(1=$ poor, $5=$ excellent $)$. Questionnaires for the older and oldest adults also contained an additional 5point scale for rating their remembered spelling ability at age 20 .

All participants then heard the stimulus words over headphones with instructions to print each word legibly on a numbered response sheet, guessing at the spelling if necessary. A "trial" consisted of a stimulus number, a 425-ms warning tone, a 3-s pause, then the stimulus word, a 10-s pause, and a repetition of the stimulus word. Next came a 20-s pause, during which participants printed the word next to its stimulus number on the response sheet. If participants needed more time to respond, they could press the "pause" button to stop the tape recorder and press "play" to restart. During practice trials, participants were encouraged to adjust the volume of the tape recorder to whatever level was comfortable for them. After the practice trials, the experimenter answered questions and then left the room. At the end of the experiment, the experimenter checked responses for legibility to create a more legible copy if necessary.

\section{Results}

We used three criteria to score mishearings: if participants spelled an English word other than the word on the tape (most frequent); if participants spelled a nonword that three judges agreed must have been a mishearing (e.g., voraclly instead of broccoli); and if participants gave no written response (least frequent). By these criteria, mishearings occurred on $4.4 \%$ of the trials, and, as might be expected, increased systematically with aging: young, $1.7 \%$; older, $3.4 \%$; and oldest, $9.1 \%$, a reliable age effect, $F(2,82)=8.29, p<.0005$. Post hoc Bonferroni tests indicated that mishearings were reliably more common ( $p$ $<.05$ ) for the oldest than for either the young or the older participants, who did not differ reliably from each other. Unless noted otherwise, we excluded mishearings from all further analyses, ${ }^{3}$ which are discussed in the Main Results and Subsidiary Results sections.

\section{Main Results}

The main results are divided into three sections: percentage of correct spelling of high- versus low-frequency words; correlations with background characteristics and questionnaire responses; and errors on regularly versus irregularly spelled letters in high-frequency words. The dependent measure was whole words in the first two sections, but errors per letter in the third section.

\section{Percentage of Correct Spelling of High-Versus Low-Frequency Words}

The mean percentage of correct spelling per participant for the three age groups is shown as a function of word frequency in Table 3, together with standard deviations and overall percentage correct. A 3 (age) $\times 2$ (frequency) multivariate analysis of variance (MANOVA) applied to these data indicated no main effect of age, $F(2,82)=2.68, M S E=0.08, p>.073$, but a main effect of frequency, $F(2,82)=86.22, M S E=0.01, p<$ .001 , and an Age $\times$ Frequency interaction, $F(2,82)=5.66$, $M S E=0.01, p<.005$. Subsequent analyses indicated no age effect for low-frequency words, $F(2,82)=1.52, M S E=.04$, $p>.224$, but a reliable age effect for high-frequency words, $F(2,82)=4.04, M S E=0.05, p<.021$. Post hoc Bonferroni tests on this age effect for high-frequency words indicated no reliable difference between the older and oldest groups, but reliably better spelling for the young adults than the oldest adults $(p<.05)$.

Why did the oldest adults exhibit a spelling deficit for highfrequency words relative to young adults, but not for low-frequency words? This pattern is important to understand because similar Age $\times$ Word Frequency interactions have been reported in other studies (e.g., Allen, Madden, \& Slane, 1995; Stadtlander, 1995). Age-linked differences in familiarity provide one possible explanation. According to this "familiarity hypothesis,' the young adults had not encountered (i.e., did not know) many of the low-frequency words and therefore did not know how to spell them, unlike the older and oldest adults, who had encountered these words many times over the course of their (longer) lives. However, high-frequency words were equally familiar to both groups, so that the oldest adults made more errors than the young adults on high-frequency words because of a decline in their ability to spell familiar words that they once knew how to spell correctly.

Support for this familiarity hypothesis came from several

\footnotetext{
${ }^{3}$ We also dropped the word/indayt/from all analyses because it turned out to have two viable spellings (indict and indite).
} 
Table 3

Percentage of Correct Spelling per Participant for Young, Older, and Oldest Adults as a Function of Word Frequency

\begin{tabular}{|c|c|c|c|c|c|c|}
\hline \multirow{2}{*}{$\begin{array}{l}\text { Age } \\
\text { group }\end{array}$} & \multicolumn{2}{|c|}{$\begin{array}{l}\text { High-frequency } \\
\text { words }\end{array}$} & \multicolumn{2}{|c|}{$\begin{array}{c}\text { Low-frequency } \\
\text { words }\end{array}$} & \multicolumn{2}{|c|}{ Overall $\%$ correct } \\
\hline & $M$ & $S D$ & $M$ & $S D$ & $M$ & $S D$ \\
\hline Young & 72.1 & 15.9 & 54.2 & 15.7 & 63.3 & 14.4 \\
\hline Older & 66.0 & 26.7 & 56.3 & 21.5 & 61.2 & 23.5 \\
\hline Oldest & 56.0 & 23.4 & 47.3 & 21.2 & 51.6 & 21.8 \\
\hline
\end{tabular}

sources. One was the raw frequency with which young adults made same-pronunciation errors on low-frequency words. Same-pronunciation errors, sometimes called "regularizations" and "legal misspellings" (Treiman, 1993, pp. 23-51), are misspellings that can be pronounced in the same way as the correctly spelled word because they follow the phonology-to-orthography pattern in many other words. For example, $97 \%$ of English words spell /i/ as [I] (e.g., fist) and only 3\% spell /i/ as [Y] (e.g., cyst; Barry, 1994). Consequently, cist instead of cyst is a same-pronunciation misspelling, and so are spontanious, pagent, and generocity. Different-pronunciation errors are misspellings that cannot be pronounced in the same way as the original word because their phonology-to-orthography pattern is rare, such as fyst (for fist; by analogy with cyst), or found in no other word, such as decsendant (for descendant), concesus (for conscious), and sasuage (for sausage).

Table 4 shows the raw frequency of same- versus differentpronunciation misspellings per participant as a function of word frequency for the three age groups, together with standard deviations and overall errors. The raw frequency of same-pronunciation errors increased with aging for low- and high-frequency words, and so did different-pronunciation errors involving highfrequency words (see Table 4). However, for low-frequency words, young adults made more same-pronunciation errors than did the older and oldest adults, a pattern confirmed by a 2 (frequency) $\times 2$ (error type) $\times 3$ (age) MANOVA. The Frequency $\times$ Age $\times$ Error Type interaction was reliable in this analysis, $F(2,82)=4.09, M S E=3.20, p<.02$, with an Age $\times$ Frequency interaction reliable only for same-pronunciation errors, $F(2,82)=5.59, M S E=3.55, p<.005$, and with a Frequency $\times$ Error Type interaction reliable only for young adults, $F(2,82)=9.74, M S E=3.20, p<.002$. This pattern suggests that young adults were unfamiliar with many of the low-frequency words and reverted to "spelling by sound," the default strategy for spelling unknown words. Because few of our stimuli contained only regularly spelled letters (see Table 2), this strategy would cause young adults to make large numbers of same-pronunciation errors on low-frequency words.

A second source of support for the familiarity hypothesis came from a multivariate analysis of covariance (MANCOVA) ${ }^{4}$ using Nelson-Denny scores as covariate, an analysis that should more closely equate relative familiarity of the low-frequency words across our age groups. Consistent with the familiarity hypothesis, the MANCOVA indicated a significant regression of Nelson-Denny scores on the percentage of correct spelling, $F(1,78)=24.69, M S E=0.06, p<.001$. The estimated or adjusted mean percentage of correct spelling per participant with Nelson-Denny scores as the covariate is shown in Figure 2 (left panel). A 2 (word frequency) $\times 3$ (age) MANCOVA on these data indicated an Age $\times$ Frequency interaction, $F(2$, $79)=5.13, M S E=0.01, p<.008$, with greater age differences for high- than low-frequency words (see Figure 2), together with main effects of frequency, $F(1,79)=79.25, M S E=0.01$, $p<.001$, and age, $F(2,78)=9.92, M S E=0.06, p<.001$. Post hoc tests showed that the age effect was reliable for highfrequency words, $F(2,78)=11.46, M S E=0.04, p<.001$, with greater correct spelling for the young than the oldest adults ( $p<.001)$ and for the young than the older adults $(p<.001)$, but no difference in correct spelling for the older and oldest adults $(p>.525)$. The age effect was also reliable for lowfrequency words, $F(2,78)=6.33, M S E=0.03, p<.003$, with greater correct spelling for the young than the oldest adults ( $p<.001)$ and for the young than the older adults $(p<.009)$, but correct spelling for the older and oldest adults did not differ ( $p>.568$ ). These findings indicate that high-frequency words were correctly spelled more often than low-frequency words and that the older and oldest adults in our sample exhibited a decline in spelling ability relative to young adults for both highand low-frequency words when differences in vocabulary were factored out, but this decline was relatively greater for highthan low-frequency words.

We also conducted covariate comparisons of same- versus different-pronunciation errors in these data. Figure 2 (right panel) shows the adjusted mean number of same-pronunciation and different-pronunciation errors per participant as a function of word frequency for the three groups, with Nelson-Denny scores as covariate. A 3 (age) $\times 2$ (frequency) $\times 2$ (error type) MANCOVA on these covariate data revealed a main effect of age, $F(2,78)=5.95, M S E=10.37, p<.004$, and a main effect of error type, $F(1,79)=234.43, M S E=5.41, p<.001$, with more same- than different-pronunciation errors ( see Figure 2 ). The main effect of frequency was also reliable, $F(1,79)=$ $54.56, M S E=1.46, p<.001$, with more errors on low- than high-frequency words. The Error Type $\times$ Age interaction and Error Type $\times$ Frequency interaction were not significant $(F<$ $1)$, but there was a significant Age $\times$ Frequency interaction, $F(2,79)=4.38, M S E=1.46, p<.016$, that was mediated by an Age $\times$ Frequency $\times$ Error Type interaction, $F(2,79)=$

\footnotetext{
${ }^{4}$ Three participants ( 1 young and 2 oldest) were lost in our multivariate analyses of covariance because of missing Nelson-Denny scores.
} 
Table 4

Mean Number of Same-Pronunciation, Different-Pronunciation, and Overall Errors per Participant as a Function of Word Frequency

\begin{tabular}{|c|c|c|c|c|c|c|c|c|c|c|}
\hline \multirow{3}{*}{$\begin{array}{l}\text { Age } \\
\text { group }\end{array}$} & \multicolumn{4}{|c|}{ High-frequency words } & \multicolumn{4}{|c|}{ Low-frequency words } & & \\
\hline & \multicolumn{2}{|c|}{$\begin{array}{c}\text { Same- } \\
\text { pronunciation } \\
\text { errors }\end{array}$} & \multicolumn{2}{|c|}{$\begin{array}{c}\text { Different- } \\
\text { pronunciation } \\
\text { errors }\end{array}$} & \multicolumn{2}{|c|}{$\begin{array}{c}\text { Same- } \\
\text { pronunciation } \\
\text { errors }\end{array}$} & \multicolumn{2}{|c|}{$\begin{array}{l}\text { Different- } \\
\text { pronunciation } \\
\text { errors }\end{array}$} & \multicolumn{2}{|c|}{ Overall errors } \\
\hline & $M$ & $S D$ & $M$ & $S D$ & $M$ & $S D$ & $M$ & $S D$ & $M$ & $S D$ \\
\hline Young & 4.40 & 2.21 & 1.03 & 1.18 & 6.89 & 2.39 & 1.63 & 1.70 & 13.94 & 5.57 \\
\hline Older & 4.80 & 3.55 & 1.48 & 1.85 & 5.92 & 2.93 & 2.20 & 2.50 & 14.40 & 8.49 \\
\hline Oldest & 5.92 & 3.11 & 1.92 & 1.71 & 6.12 & 2.24 & 2.88 & 2.42 & 16.84 & 7.05 \\
\hline
\end{tabular}

3.61, MSE $=3.49, p<.031$. Further analysis of this three-way interaction showed that the older and oldest adults made more same-pronunciation errors than young adults for high-frequency words and more different-pronunciation errors for both high-

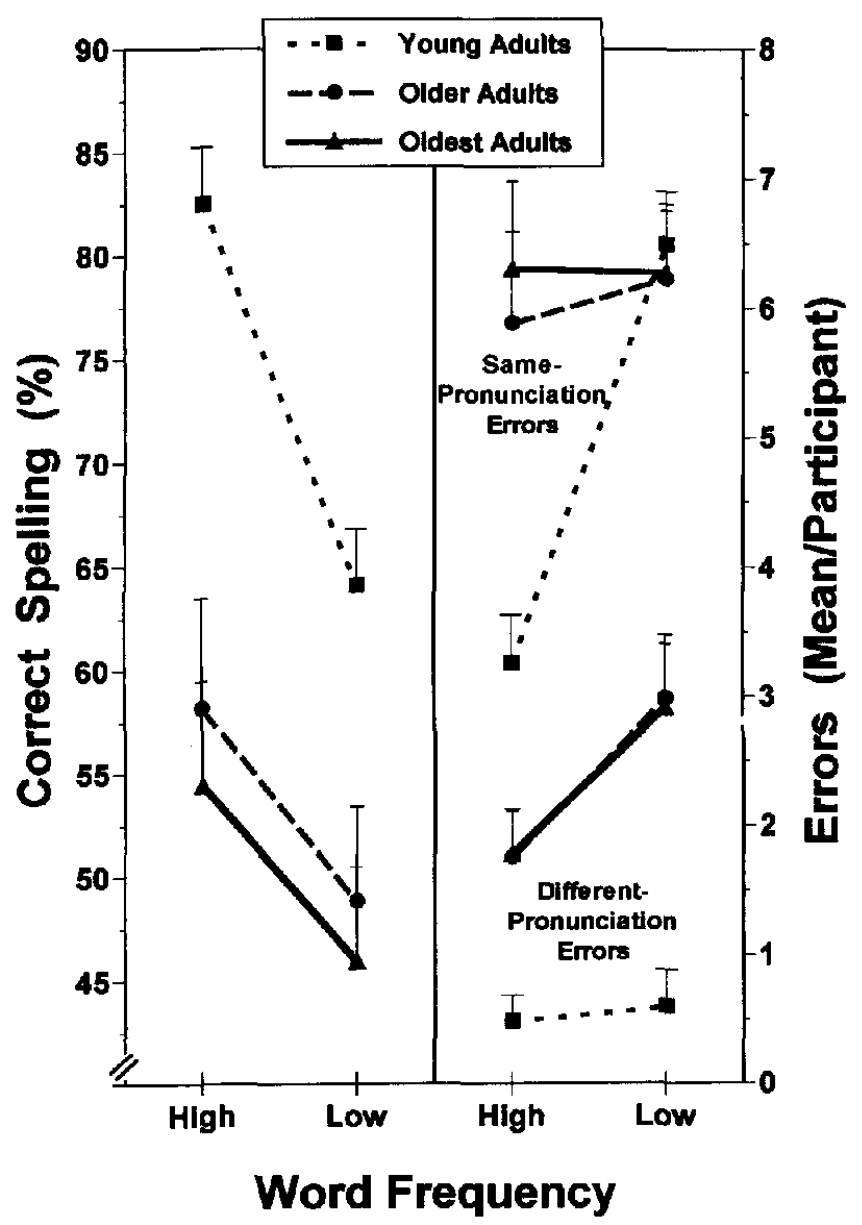

Figure 2. The adjusted mean percentage of correct spelling per participant using Nelson-Denny scores as a covariate (left ordinate) and adjusted mean number of same-pronunciation and different-pronunciation errors per participant using Nelson-Denny scores as a covariate (right ordinate) for young, older, and oldest adults spelling high- and low-frequency words. The error bars indicate $1 S E$ above the mean. and low-frequency words (largest $p<.007$ ), but there were no age differences in the number of same-pronunciation errors for low-frequency words $(p>.943)$.

To summarize, our MANCOVAs tended to equate the relative familiarity of low-frequency words across age groups (compare Table 3 with Figure 2), but may not have been entirely successful because the young adults continued to make a disproportionate number of same-pronunciation errors in spelling low-frequency words. However, the trend suggests that relative to the older and oldest adults, young adults would make reliably fewer same-pronunciation errors on low-frequency words with a more successful procedure for equating familiarity. ${ }^{5}$

\section{Correlations With Background Characteristics and Questionnaire Responses}

The mean hours per week spent reading, writing, and doing crossword puzzles are shown for the three age groups in Table 1. Also shown in Table 1 are the mean ratings of current spelling ability for the three groups; the rigor with which their grade school taught spelling skills; and, for the older and oldest adults, their spelling ability at age 20 . To determine whether participants could accurately evaluate their current spelling ability, we correlated self-ratings of current spelling ability with the percentage of correct spelling in the main experiment. The correlations were highly reliable within each age group (smallest $r=.65$, largest $p<.023$ ) and across all three age groups, $r(47)=.66$, $p<.001$, suggesting that self-ratings of current spelling ability provided a reasonably accurate estimate of actual spelling ability. Although we had no comparable test of validity for selfratings of spelling ability at age 20 for the older and oldest adults, we nonetheless were able to test whether the older and

\footnotetext{
${ }^{5}$ Multivariate analyses of covariance based on estimates of stimulus familiarity collected at the end of the experiment might seem like a problem-free means of equating relative familiarity across age groups, but it is not: Familiarity judgments are relatively more difficult for older adults because of their episodic memory deficits and longer life spans, and comparing these judgments across age groups may be problematic in view of available evidence indicating that young and older adults make these judgments in fundamentally different ways (Parkin \& Walter, 1992). We thank an anonymous reviewer for suggesting an end-ofexperiment test of word knowledge resembling the Nelson-Denny but restricting it to the stimuli actually presented in the experiment.
} 
oldest adults were aware of a decline in their ability to spell by comparing self-ratings of spelling ability that they provided for age 20 and for their current age. Ratings were lower for current than former spelling ability for both the older and oldest adults (see Table 1), but the difference was reliable only for the oldest adults, $t(17)=-2.20, S E=0.202, p<.042$. These findings suggest that the oldest but not the older adults were aware of a decline in their spelling skills.

To determine what other age-linked factors in our study might be related to spelling ability, we compared estimates for the three groups of hours per week spent reading, writing, and solving crossword puzzles and of how rigorously their grade school taught spelling skills. The three groups differed at the .05 level only for one of these reported attributes: hours spent writing per day, $F(2,38)=8.31, p<.001$. Post hoc Bonferroni tests indicated no reliable difference between the older and oldest adults at the .05 level, but young adults reported reliably more hours per day writing ( $M=3.75 \mathrm{hr}$ ) than either the older adults $(M=1.67 \mathrm{hr})$ or the oldest adults $(M=1.00 \mathrm{hr})$. This difference in estimated time spent writing makes sense in view of the ongoing educational activities of the young adults, but correlations between the percent of correct spelling and time spent writing were unreliable ( $p>.05$ for all three age groups), which makes it unlikely that young adults correctly spelled highfrequency words more often than the oldest adults because of the reliably greater time that they spent writing.

For young adults, the percentage of correct spelling correlated reliably with no other background or questionnaire information at the .05 level (see Table 1), whereas for the older and oldest adults, only the following characteristics correlated with the percentage of correct spelling at the .05 level: forward digit span for the older adults, $r(25)=.584$, and oldest adults, $r(23)$ $=.651$; hours spent doing crossword puzzles for older adults, $r(15)=.539$; health rating for older adults, $r(25)=.436$; backward digit span for older adults, $r(25)=.558$; NelsonDenny Vocabulary scores for the older adults, $r(25)=.514$, and the oldest adults, $r(23)=.740$; rigorousness of grade school teaching of spelling for the oldest adults, $r(13)=.788$; and years of education for the oldest adults, $r(24)=.428$. These positive correlations with vocabulary scores and education highlight the remarkable nature of the decline in correct spelling of the oldest adults in our initial MANOVAs: Despite their greater education, higher vocabulary scores, and more frequent encounters with high-frequency words over the course of their lifetimes, the oldest adults correctly spelled high-frequency words reliably less often than did young adults.

\section{Errors on Regularly Versus Irregularly Spelled Letters in High-Frequency Words}

Because of the possible confound of age and familiarity with low-frequency words discussed earlier, we confined our by-letter analyses to high-frequency words. Two judges first labeled each letter in the high-frequency words as either regularly spelled or irregularly spelled. ${ }^{6}$ For example, regularly spelled letters were capitalized in DEscENDANT, and irregularly spelled letters were in lowercase. The judges next determined whether spelling errors in the data involved regularly or irregularly spelled letters in the words. For example, the misspelling decsendant involves the irregularly spelled letters in descendant, whereas the misspelling descendent involves a regularly spelled letter. Other examples were more complex in nature. For instance, desendent contains two misspellings, one involving a regularly spelled letter and the other an irregularly spelled letter. Finally, three judges determined whether misspellings of regularly and irregularly spelled letters had the same pronunciation as the original word or different pronunciation from the original word. For example, the misspelling decsendant is a different-pronunciation error because it cannot be pronounced the same as descendant. However, the misspelling descendent can be pronounced the same as descendant and is a same-pronunciation error.

The probability of errors was the dependent measure in our by-letter analyses because different stimulus words contained different numbers of regularly versus irregularly spelled letters. To obtain these probabilities, we divided the number of errors per participant (summating multiple misspellings within the same word) on regularly versus irregularly spelled letters by the total number of letters of each type in the stimulus words. These probabilities are therefore a direct function of raw frequency rather than proportions of same- versus different-pronunciation errors.

Figure 3 shows the mean probability of same- and differentpronunciation errors per regularly spelled letter (left ordinate) and per irregularly spelled letter (right ordinate: Note expanded scale) for participants in the three age groups. A 3 (age) $\times 2$ (component: regular vs. irregular) $\times 2$ (pronunciation: same vs. different from the original word) MANOVA on these data indicated that all three main effects were significant: age, $F(2$, $82)=4.34, M S E=0.01, p<.016$, such that the oldest adults made more errors than the young adults; pronunciation, $F(1$, $82)=127.28, M S E=0.01, p<.001$, such that same-pronunciation errors were more frequent than different-pronunciation errors; and component, $F(1,82)=77.13, M S E=0.01, p<.001$, such that more errors involved irregularly than regularly spelled letters in the words.

In addition, all of the two-way interactions were reliable at the .05 level, except for one that was reliable at .059 . However, these two-way interactions were mediated by an Age $\times$ Component $\times$ Pronunciation interaction, $F(2,82)=7.28, M S E=$ $0.01, p<.001$, and further analyses of this three-way interaction indicated a significant Age $\times$ Pronunciation interaction only for irregular components, $F(2,82)=7.16, M S E=0.01, p<.001$, such that the oldest participants made more same-pronunciation errors than did the young participants on irregular components, but different pronunciation errors on irregular components did not differ as a function of age. However, the oldest participants made more same- and different-pronunciation errors on regularly spelled letters than did young and older participants $(p<$ $.018)$, with no difference between these latter groups ( $p>.809$; see Figure 3 ).

\footnotetext{
${ }^{6}$ We dropped the word rhythm in our by-letter analyses because our judges disagreed about which of its letters were regularly versus irregularly spelled. Interjudge reliability following interaction between the judges was $100 \%$ for the remaining words. We would nonetheless have preferred to define regularity in terms of the relative frequency of a given spelling for a given context-dependent speech sound. However, no such "degree of regularity" norms currently exist.
} 


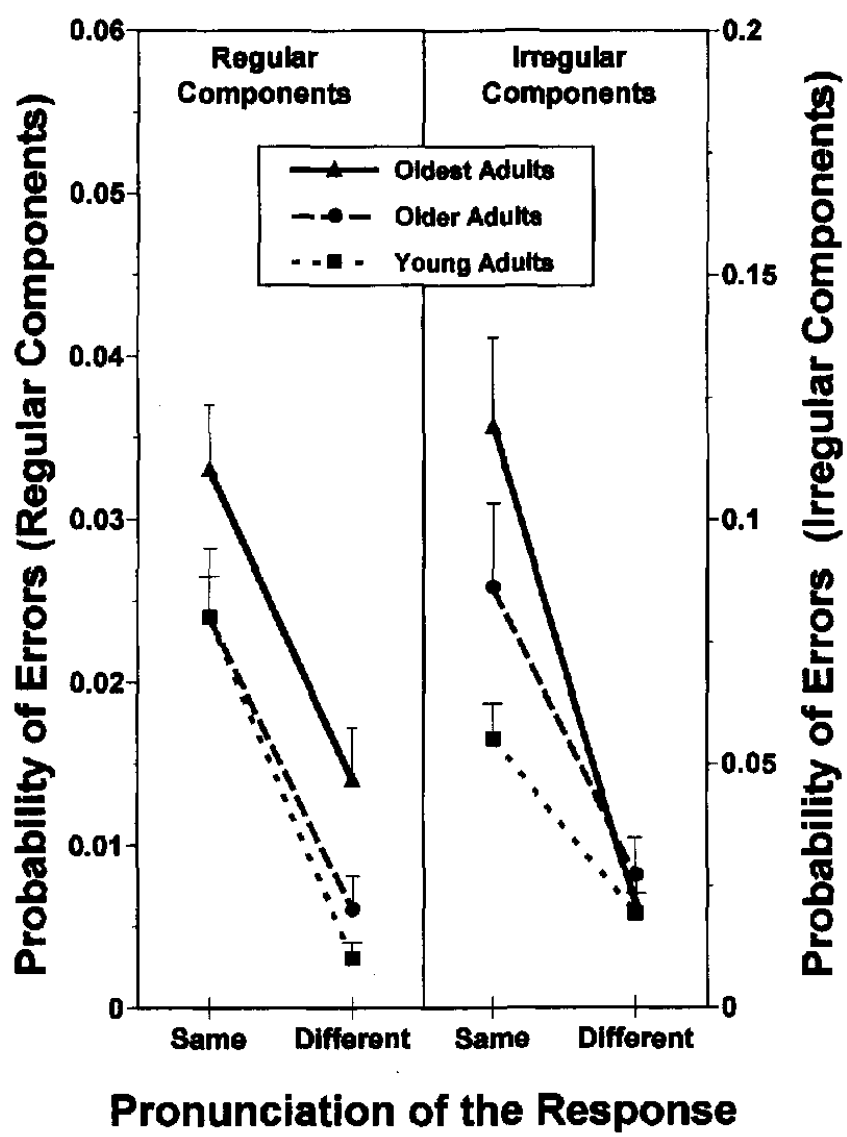

Figure 3. The probability per letter of same-pronunciation and different-pronunciation misspellings for the young, older, and oldest adults on regularly spelled (left ordinate) versus irregularly spelled letters (right ordinate: Note the expanded scale) in high-frequency words. The error bars indicate $1 S E$ above the mean.

To summarize, the pattern of errors with letters and words as dependent measures was similar except for two new age-linked effects at the letter level. First, for irregularly spelled letters, the oldest adults produced more same-pronunciation misspellings than did the young adults, but different-pronunciation misspellings involving irregularly spelled letters did not differ as a function of age. ' Second, for regularly spelled letters, both sameand different-pronunciation misspellings were more common for the oldest adults than for the young and older adults. These results refine our findings with words as dependent measure, in which same- and different-pronunciation misspellings of highfrequency words did not differ reliably for the oldest and older adults (see Figure 2).

As predicted under NST, many of the different-pronunciation errors could be described as reflecting misactivation of a quasiirregular node or misapplication of an inappropriate quasi-irregularity rule. For example, the doubled [R] in the misspelling of unecessary as unescerry can be described as a misapplication of the doubling rule that should apply to $[S]$ in this word. Similarly, when assessment was misspelled assecement, the replacement of [SS] with [C] can be described as a misactivation of the quasi-irregular node for spelling $/ \mathrm{s} /$ as $[\mathrm{C}]$ in proceed, recede, and concede. When picnicking was misspelled piquniquing, replacements of $[\mathrm{C}]$ and $[\mathrm{CK}]$ with $[\mathrm{QU}]$ can be described as misactivations of the quasi-irregular node for spelling $/ \mathrm{k} /$ as [QU] in words such as piqued. Finally, the misspelling of grievance as greivance can be described as a misactivation of the quasi-irregular node for spelling /e/ as [EI] in receive and conceive.

\section{Subsidiary Results}

Some aspects of our data neither contradicted the NST of orthographic retrieval nor constituted direct predictions of NST in its current state of development. However, these subsidiary results seemed noteworthy as a stimulus to further research and theoretical development, and we report them here with minimal speculation or theoretical comment.

\section{Proportions of Same-Versus Different-Pronunciation Errors}

Unlike previous analyses testing NST predictions for raw frequencies, we analyzed proportions of same- versus differentpronunciation errors. Our statistical analyses focused on different- rather than same-pronunciation proportions (optionally because of the linear dependence or mirror-image relation between proportions of same- and different-pronunciation errors ). These analyses revealed two empirical regularities, discussed next.

The different-pronunciation proportion increases with aging As can be seen in Table 5, the proportion of different-pronunciation misspellings per participant increased montonically with aging for both high- and low-frequency words. A 3 (age) $\times 2$ (frequency) MANOVA on these data yielded a main effect of age, $F(2,77)=4.12, M S E=0.04, p<.02$, with 5 older participants excluded because they made no errors on highfrequency words. Post hoc tests on this age effect indicated that the young adults had a reliably lower proportion of differentpronunciation misspellings than did the oldest adults $(p<$ .009 ), and a marginally lower proportion than the older adults $(p<.051)$, with no difference between the older and oldest groups $(p>.63)$. There was no Age $\times$ Frequency interaction $(F<1)$, and the main effect of frequency was marginally significant, $F(1,77)=3.75, M S E=0.02, p<.056$, with a lower proportion of different-pronunciation errors on high- than low-frequency words.

This main effect of age became statistically stronger in analyses with Nelson-Denny scores as covariate despite the additional exclusion of 1 young and 2 oldest participants because of missing Nelson-Denny scores ( see Footnote 4). Table 5 also shows the adjusted mean proportion of different-pronunciation misspellings for the three age groups with Nelson-Denny scores as covariate, and a 3 (age) $\times 2$ (word frequency) MANCOVA on the different-pronunciation proportions yielded a main effect of age, $F(1,73)=7.26, M S E=0.03, p<.001$, with a reliably lower proportion of different-pronunciation misspellings for the

\footnotetext{
${ }^{3}$ The spelling retrieval data of MacKay, Abrams, and Pedroza (in press) exhibited this same pattern, with an Age $\times$ Error Type interaction $(p<.027)$ attributable to more same-pronunciation errors for older than young adults.
} 
Table 5

Mean Proportion and Adjusted Mean Proportion (With Nelson-Denny Scores as a Covariate) of Same- and DifferentPronunciation Errors per Participant as a Function of Word Frequency

\begin{tabular}{|c|c|c|c|c|c|c|c|c|}
\hline \multirow{3}{*}{$\begin{array}{l}\text { Age } \\
\text { group }\end{array}$} & \multicolumn{4}{|c|}{ High-frequency words } & \multicolumn{4}{|c|}{ Low-frequency words } \\
\hline & \multicolumn{2}{|c|}{$\begin{array}{l}\text { Same-pronunciation } \\
\text { errors }\end{array}$} & \multicolumn{2}{|c|}{$\begin{array}{c}\text { Different- } \\
\text { pronunciation errors }\end{array}$} & \multicolumn{2}{|c|}{$\begin{array}{c}\text { Same-pronunciation } \\
\text { errors }\end{array}$} & \multicolumn{2}{|c|}{$\begin{array}{c}\text { Different- } \\
\text { pronunciation errors }\end{array}$} \\
\hline & $M$ & $S D$ & $M$ & $S D$ & $M$ & $S D$ & $M$ & $S D$ \\
\hline \multicolumn{9}{|c|}{ Mean proportion of errors per participant } \\
\hline Young & .854 & .140 & .146 & .140 & .827 & .144 & .173 & .144 \\
\hline Older & .783 & .156 & .217 & .156 & .744 & .211 & .256 & .211 \\
\hline Oldest & .775 & .172 & .225 & .172 & .712 & .203 & .288 & .203 \\
\hline \multicolumn{9}{|c|}{ Adjusted mean proportion of errors per participant } \\
\hline Young & .877 & .141 & .123 & .141 & .890 & .146 & .110 & .146 \\
\hline Older & .767 & .156 & .233 & .156 & .698 & .211 & .302 & .211 \\
\hline Oldest & .787 & .164 & .213 & .164 & .714 & .201 & .286 & .201 \\
\hline
\end{tabular}

young than either the older or oldest participants $(p<.002)$, who did not differ from each other $(p>.665)$. However, the main effect of frequency became marginal in the MANCOVA, $F(1,74)=3.48, M S E=0.02, p<.066$, with no Age $\times$ Frequency interaction $(F<1)$.

Irregularly spelled letters increase the different-pronunciation proportion. The mean proportions of same- versus different-pronunciation misspellings on regularly versus irregularly spelled letters in high-frequency words are shown in Table 6 for the three age groups. A 3 (age) $\times 2$ (component: regularly vs. irregularly spelled letters) MANOVA on the different-pronunciation proportions yielded only a reliable effect of component, $F(1,82)=23.16, M S E=0.01, p<.001$, with a higher proportion of different-pronunciation errors on irregularly than regularly spelled letters. There was no main effect of age, $F(2$, $82)=1.09, M S E=0.01, p>.34$, and no Age $\times$ Component interaction, $F(2,82)=1.93, M S E=0.01, p>.15$.

\section{Different-Pronunciation Errors of Unknown Origin}

Some different-pronunciation errors of our older and oldest adults were both remarkable and unexpected under our theoretical framework. These different-pronunciation errors of unknown origin became apparent in our letter-level analyses and involved addition, substitution, transposition, or omission of letters in ways that seemed less related to retrieval of quasiirregular English spelling patterns than to "slips of the pen" reflecting transient inattention during writing (see MacKay, 1993). For example, when grievance was misspelled grievenance, the added [EN] was of unknown origin, but it may reflect a false start that the participant failed to cross out in the written output. That is, the person may have begun to spell grievance as grievence, realized that [EN] should be [AN], but forgot to cross out [EN] after writing grievenance. An example of letter substitution is revervor for reservoir, as if [V] replaced [S] in anticipation of the upcoming [V] in reservoir. Transpositions involved correctly retrieved letters, but in a transposed position within the word (e.g., delimma for dilemma). Examples of letter omissions are pinicking for picnicking and assement for assessment. Other errors of unknown origin were more complex or ambiguous as to which letters were omitted, added, substituted, or transposed. An example is delimia for dilemma. Perhaps the [I] and [E] in dilemma were transposed during writing and a second [I] was substituted in error for the second [M]. Or perhaps the participant began to spell dilemma as delim-, realized that [I] was somehow in error, but carried through with delimia on the mistaken assumption that an [I] should be added.

Table 6

Mean Proportion of Same- and Different-Pronunciation Errors per Participant for Regularly and lrregularly Spelled Letters in High-Frequency Words

\begin{tabular}{|c|c|c|c|c|c|c|c|c|}
\hline \multirow{3}{*}{$\begin{array}{l}\text { Age } \\
\text { group }\end{array}$} & \multicolumn{4}{|c|}{ Regularly spelled letters } & \multicolumn{4}{|c|}{ Irregularly spelled letters } \\
\hline & \multicolumn{2}{|c|}{$\begin{array}{l}\text { Same-pronunciation } \\
\text { errors }\end{array}$} & \multicolumn{2}{|c|}{$\begin{array}{c}\text { Different- } \\
\text { pronunciation errors }\end{array}$} & \multicolumn{2}{|c|}{$\begin{array}{c}\text { Same-pronunciation } \\
\text { errors }\end{array}$} & \multicolumn{2}{|c|}{$\begin{array}{l}\text { Different- } \\
\text { pronunciation errors }\end{array}$} \\
\hline & $M$ & $S D$ & $M$ & $S D$ & $M$ & $S D$ & $M$ & $S D$ \\
\hline Young & .997 & .006 & .003 & .006 & .981 & .026 & .019 & .026 \\
\hline Older & .994 & .011 & .006 & .011 & .973 & .039 & .027 & .039 \\
\hline Oldest & .986 & .016 & .014 & .016 & .979 & .027 & .021 & .027 \\
\hline
\end{tabular}


Table 7

Percentage of Correct Spelling per Participant as a Function of Age for Words Containing Versus Not Containing a Crossout, Together With Overall (Frequency-Weighted) Percentage Correct

\begin{tabular}{|c|c|c|c|c|c|c|}
\hline \multirow{2}{*}{$\begin{array}{l}\text { Age } \\
\text { group }\end{array}$} & \multicolumn{2}{|c|}{$\begin{array}{l}\text { Words containing a } \\
\text { crossout }\end{array}$} & \multicolumn{2}{|c|}{$\begin{array}{c}\text { Words not containing } \\
\text { a crossout }\end{array}$} & \multicolumn{2}{|c|}{ Overall $\%$ correct } \\
\hline & $M$ & $S D$ & $M$ & $S D$ & $M$ & $S D$ \\
\hline Young & 44.7 & 26.2 & 66.7 & 15.3 & 63.3 & 14.4 \\
\hline Older & 44.5 & 33.9 & 63.0 & 23.0 & 61.2 & 23.5 \\
\hline Oldest & 34.8 & 32.7 & 54.1 & 21.9 & 51.6 & 21.8 \\
\hline
\end{tabular}

\section{Error Detection and Correction: The Crossout Data}

If some misspellings in our data reflect slips of the pen by people who actually knew the correct spelling, then failure to detect and correct these errors may have contributed to our agelinked increase in misspellings. The older and oldest adults may have monitored their written output less carefully or were less able to detect and correct their errors than young adults when inspecting their written output. As an initial test of this monitoring hypothesis, we examined how often participants crossed out and corrected their initial spelling of words in the original transcripts. These crossouts were readily scored because most participants wrote with a pen, and the erasures and crossouts by the 3 participants who wrote with a pencil were easy to discern.

Table 7 shows the percentage of correct spelling per participant as a function of age group for responses containing versus not containing a crossout. Contrary to the hypothesis that older adults monitored, detected, or corrected their errors less often than did young adults, a 3 (age) $\times 2$ (response type: crossed out vs. not crossed out) MANOVA on these data indicated no main effect of age, $F(2,80)=2.05, M S E=0.09, p>.134$, and no Age $\times$ Response Type interaction $(F<1)$. However, there was a main effect of response type, $F(1,80)=41.65$, $M S E=0.04, p<.001$, such that responses containing a crossout were spelled correctly reliably less often than responses not containing a crossout (see Table 7). One possible account of this result is that participants more often crossed out their initial spellings for words that were especially difficult to spell, an effect that did not differ as a function of age.

Crossout frequency also did not vary with age for responses that we had labeled correctly heard versus misheard. Table 8

Table 8

Percentage of Crossouts per Participant for Misheard Versus Correctly Heard Stimuli as a Function of Age Group

\begin{tabular}{|c|c|c|c|c|}
\hline \multirow{2}{*}{$\begin{array}{c}\text { Age } \\
\text { group }\end{array}$} & \multicolumn{2}{|c|}{ Misheard stimuli } & \multicolumn{2}{|c|}{$\begin{array}{l}\text { Correctly heard } \\
\text { stimuli }\end{array}$} \\
\hline & $M$ & $S D$ & $M$ & $S D$ \\
\hline Young & 7.1 & 23.9 & 15.0 & 6.1 \\
\hline Older & 9.7 & 18.1 & 17.3 & 11.0 \\
\hline Oldest & 22.6 & 39.4 & 13.4 & 10.1 \\
\hline
\end{tabular}

shows the percentage of crossouts per participant as a function of age group for responses in the misheard versus correctly heard categories. A 3 (age) $\times 2$ (response type: misheard vs. correctly heard) MANOVA on these data indicated no main effect of age $(F<1)$, or of response type $(F<1)$, and no Age $\times$ Response Type interaction, $F(2,48)=2.27, M S E=$ $0.04, p>.114$. In short, all three age groups crossed out and corrected misheard words no more often than correctly heard words.

\section{Discussion}

In summary, our main results were as follows: With perceptual errors and differences in vocabulary factored out, the older and oldest adults made more spelling errors than did young adults for both high- and low-frequency words. Whether this age-linked spelling deficit applies only to difficult-to-spell words such as those in the present study remains to be explored. However, responses to a metamemory questionnaire indicated that the oldest but not the older adults were aware of a general decline in their ability to spell. Results with letters in highfrequency words as the dependent measure indicated that for regularly spelled letters, the oldest adults produced more sameand different-pronunciation misspellings than did the young and older adults, but for irregularly spelled letters, the oldest adults produced only more same-pronunciation misspellings than did the young adults, with no age differences in different-pronunciation misspellings. We first discuss some unlikely accounts of these results and then offer a more plausible one.

\section{Unlikely Accounts of Our Results}

Why did the older and oldest adults make more spelling errors than the young adults? Under one hypothesis, the older and oldest adults never learned how to spell the words in the present study because of cohort-related educational deficiencies. However, this possibility seems unlikely for three reasons: (a) The older and oldest adults had higher levels of education than the young adults; (b) there was no difference in the rated rigor with which the grade schools of young, older, and oldest adults taught spelling skills; and (c) the deficit for the older and oldest adults was greatest for high-frequency words, the very words that educational programs are likely to emphasize.

Nonetheless, we cannot rule out all possible cohort effects without a longitudinal study of spelling retrieval, and we are 
currently conducting such a study. The TDH predicts longitudinal age effects on spelling resembling those in the present study and in the longitudinal study of An et al. (1995), which ruled out cohort accounts of age-linked declines in spoken word retrieval on the BNT. Consistent with this TDH prediction, our results already rule out four cohort-relevant factors with possible links to spelling ability: how many hours per week participants spent reading, writing, and solving crossword puzzles as well as how rigorously their grade school taught spelling skills. Factors that correlated with cohort (e.g., hours per week spent writing ) were unrelated to spelling ability, and factors that correlated with spelling ability (e.g., hours per week spent solving crossword puzzles) could not explain our age effects. Likewise difficult to explain as a cohort effect are the metamemory data indicating that our oldest participants were aware of a decline in their spelling skills since the age of 20 years.

It also seems unlikely that our results are due to a general slowing factor, ${ }^{B}$ even one embedded within a connectionist architecture resembling NST. Words in the present study were spoken at a relatively slow rate; participants could stop and restart the tape recorder if they needed more time; and they wrote down the words at their own pace, with response speed deemphasized in the instructions. It is also difficult to explain our age effects via the processing-speed theory of Salthouse (1996). In processing-speed theory, general slowing degrades cognitive performance because the products of earlier processing are no longer available at the time when later processing requires those products. It is unclear what interdependent earlier and later processing products processing-speed theory might postulate for spelling retrieval, which virtually always runs off letter by letter from left to right in a word.

Age-linked difficulties with sensory and perceptual processing likewise cannot account for our results because perceptual errors were factored out in our analyses. Another unlikely account is that age-linked declines in the ability to spell reflect difficulties in error monitoring such that relative to young adults, older adults either check their written output less carefully for errors or are less able to detect and correct the errors in their written output than young adults. Contrary to this hypothesis, young adults crossed out and corrected their spellings in our transcripts no more often than did the older and oldest adults. In addition, MacKay et al. (in press) directly tested for the effects of aging on the ability to detect spelling errors in visually presented words and found that older adults were able to detect misspellings at least as well as young adults.

More difficult to rule out is the hypothesis that older adults write and type difficult-to-spell words less often than young adults and monitor their written and typed output less carefully than young adults in their everyday lives, so that greater time spans have elapsed since the older and oldest adults generated the correct spelling for the words in the present study. However, this recency hypothesis is inconsistent with the crossout data in Table 7 and with our low correlations between correct spelling and hours per week spent writing. The recency hypothesis also fails to explain the parallel age-linked declines in written and spoken word retrieval because it is unlikely that healthy older adults do not speak as much as young adults (see Burke et al., 1991).

Our results are also difficult to explain under an inhibition deficit hypothesis, even one embedded within a cognitive architecture resembling NST. If inhibitory but not excitatory connections exhibit age-linked impairment (e.g., Hasher, Stoltzfus, Zacks, \& Rypma, 1991; Hasher \& Zacks, 1988), then one might expect an age-linked increase in same-pronunciation errors due to inhibition failure (see the inhibitory link in Figure 1), but not an age-linked increase in different-pronunciation errors, contrary to our data with both words and letters as dependent measures.

\section{The NST Account of Our Results}

The TDH embedded within the NST of orthographic retrieval provides a plausible account of the present data with words as dependent measure. As predicted under the TDH, age-linked declines in retrieval of orthography resemble declines in the retrieval of phonology in spoken language production (see, e.g., Albert et al., 1988; Balota \& Duchek, 1988; Bowles et al., 1989; Bowles \& Poon, 1985; Burke et al., 1991; Cohen \& Faulkner, 1986; Liss et al., 1990; Maylor, 1990; McCrae et al., 1987; Mitchell, 1989; Nicholas et al., 1985; for reviews, see Burke \& MacKay, 1997; MacKay \& Abrams, 1996; and MacKay \& Burke, 1990).

It is interesting that declines in spelling retrieval become readily detectable around the same age when declines in spoken word retrieval became readily detectable in the BNT data of Nicholas et al. (1985) and All et al. (1995). However, this correspondence may be fortuitous because a variety of factors that are undifferentiated in BNT data can play a role in the detectable age of decline. With materials matched for familiarity, the detectable age of decline will differ for production versus perception, for semantic versus orthographic and phonological units, and for high-versus low-frequency words under the TDH, and, consistent with this point, Burke et al. (1991) reported an agelinked decline in retrieval of very-low-frequency words with 37 as the detectable age of onset.

As predicted under the TDH, low-frequency words were misspelled more often than high-frequency words, and the older and oldest adults made more same-pronunciation errors than did young adults for high-frequency words (e.g., misspelling calendar as the regularly spelled calender). Also consistent with TDH predictions, the older and oldest adults made more different-pronunciation errors than did young adults in spelling both high- and low-frequency words.

We turn now to results with letters rather than words as dependent measure. As predicted under NST, the older and oldest adults were especially likely to make same-pronunciation errors relative to young adults, as if age has a multiplicative effect on the frequency differences between same- versus differentpronunciation components. Also as predicted under NST, the older and oldest adults were especially likely to misspell irregularly spelled letters relative to young adults, with no difference in the probability of misspelling regularly spelled letters for

\footnotetext{
${ }^{8}$ Of course, this is not to say that older adults might not exhibit slower retrieval times than young adults or that errors are not more likely for quickly than slowly produced spelling responses. However, the crossout data in Table 7 suggest that age-linked speed-accuracy trade-offs are unlikely in the present results.
} 
young and older adults. However, deficits in spelling regularly spelled letters did appear in the very oldest adults, consistent with the hypothesis that even the frequently used lateral connections representing regular spelling constitute a single source of priming that eventually succumbs to age-linked transmission deficits. That is, regularly spelled letters involve a one-to-one lateral connection in NST (see Figure 1), and one-to-one connections are especially susceptible to age-linked transmission deficits. However, because these lateral phonology-to-orthography connections receive so much use, the effects of transmission deficits in these extremely strong connections became evident only in the oldest adults.

Another letter-level finding was that the oldest adults were especially likely to make same-pronunciation misspellings on irregularly spelled letters relative to young adults, consistent with the hypothesis noted in the introduction that the most likely outcome of transmission deficits in connections to or from quasi-irregular nodes is a same-pronunciation misspelling. The oldest adults also made more different-pronunciation errors than the young and older adults when spelling regularly spelled letters, but these misspellings involve an additional process under NST: inappropriate activation of a quasi-irregular node. That is, for the oldest adults, transmission deficits may have reduced priming delivered to the appropriate nodes, so that an inappropriate quasi-irregular node inadvertently received the most priming and became activated when the most-primed-wins activation mechanism was applied, giving rise to these different-pronunciation errors on regularly spelled letters.

Despite these fits with NST, further research is needed to evaluate the possible effects of contextual factors on the nature of different-pronunciation errors. For example, different-pronunciation errors may be reduced or eliminated in words that contain only regularly spelled letters or in an experiment that presents only regularly spelled words. Further research is also needed to understand different-pronunciation errors of unknown origin and to determine why different-pronunciation errors did not differ in frequency as a function of age for irregularly spelled letters in high-frequency words ( see Figure 3). Further research using procedures that definitively equate word familiarity across age groups is also needed to test the hypothesis that young adults made a disproportionate number of same-pronunciation errors for low-frequency words (see Figure 2) because of their lack of familiarity with those words. Finally, further research is needed to conclusively establish whether age-linked transmission deficits in the production of orthography reflect age per se, nonrecent activation of the nodes in question, or both. However, such theoretical issues should not obscure or divert attention away from the practical implications of our data: that age-linked declines in spelling ability are to be expected as part of normal cognitive aging and that steps to evaluate the consequences of those declines and to recommend remedial procedures (e.g., the use of computerized spell checkers whenever possible) are in order.

\section{References}

Albert, M. S., Heller, H. S., \& Milberg, W. (1988). Changes in naming ability with age. Psychology and Aging, 3, 173-178.

Allen, P. A., Madden, D. J., \& Slane, S. (1995). Visual word encoding and the effect of adult age and word frequency. In P. A. Allen \& T. R. Bashore (Eds.), Age differences in word and language processing (pp. 30-71). Amsterdam: North-Holland.

Au, R., Joung, P., Nicholas, M., Obler, L. K., Kass, R., \& Albert, M. L. (1995). Naming ability across the adult life span. Aging and Cognition, 2, 300-311.

Badecker, W., Hillis, A. E., \& Caramazza, A. (1990). Lexical morphology and its role in the writing process: Evidence from a case of acquired dysgraphia. Cognition, 35, 205-243.

Balota, D. A., \& Duchek, J. M. (1988). Age-related differences in lexical access, spreading activation, and simple pronunciation. Psychology and Aging, 3, 84-93.

Balota, D. A., \& Ferraro, F. R. (1993). A dissociation of frequency and regularity effects in pronunciation performance across young adults, older adults, and individuals with senile dementia of the Alzheimer type. Journal of Memory and Language, 32, 573-592.

Baron, J., Treiman, R., Wilf, J. F., \& Kellman, P. (1980). Spelling and reading by rules. In U. Frith (Ed.), Cognitive processes in spelling (pp. 159-194). New York: Academic Press.

Barry, C. (1994). Spelling routes (or roots or rutes). In G. D. A. Brown \& N. C. Ellis (Eds.), Handbook of spelling: Theory, process, and intervention (pp. 27-49). New York: Wiley.

Botwinick, J. (1984). Aging and behavior. New York: Springer.

Bowles, N. L. (1993). Semantic processes that serve picture naming. In J. Cerella, J. M. Rybash, W. Hoyer, \& M. L. Commons (Eds.), Adult information processing: Limits on loss (pp. 303-326). San Diego, CA: Academic Press.

Bowles, N. L., Obler, L. K., \& Poon, L. W. (1989). Aging and word retrieval: Naturalistic, clinical and laboratory data. In L. W. Poon, D. C. Rubin, \& B. A. Wilson (Eds.), Everyday cognition in adulthood and late life (pp. 244-264). New York: Cambridge University Press.

Bowles, N. L., \& Poon, L. W. (1985). Aging and retrieval of words in semantic memory. Journal of Gerontology, 40, 71-77.

Burke, D. M., \& MacKay, D. G. (1997). Memory, language, and ageing. Philosophical Transactions of the Royal Society, Biological Sciences, 352, 1845-1856.

Burke, D. M., MacKay, D. G., Worthley, J. S., \& Wade, E. (1991). On the tip of the tongue: What causes word finding failures in young and older adults? Journal of Memory and Language, 30, 542-579.

Caramazza, A., \& Hillis, A. E. (1990). Levels of representation, coordinate frames, and unilateral neglect. Cognitive Neuropsychology, 7 , $391-445$.

Christensen, H. (1998, April). Individual differences in change scores as a function of age. Paper presented to the Seventh Biennial Cognitive Aging Conference, Atlanta, GA.

Cohen, G., \& Faulkner, D. (1986). Memory for proper names: Age differences in retrieval. British Journal of Developmental Psychology, 4, 187-197.

Coltheart, M., Curtis, B., Atkins, P., \& Haller, M. (1993). Models of reading aloud: Dual-route and parallel-distributed-processing approaches. Psychological Review, 100, 589-608.

Cortese, M. J., \& Simpson, G. B. (1996, November). The relationship between spelling-to-sound regularity and word-body consistency in word naming. Paper presented to the 37th Annual Meeting of the Psychonomic Society, Chicago.

Fisher, F. W., Shankweiler, D., \& Liberman, I. Y. ( 1985). Spelling proficiency and sensitivity to word structure. Journal of Memory and Language, 24, 423-441.

Francis, W. N., \& Kucera, H. (1982). Frequency analysis of English usage: Lexicon and grammar. Boston: Houghton Mifflin.

Glushko, R. J. (1979). The organization and activation of orthographic knowledge in reading aloud. Joumal of Experimental Psychology: Human Perception and Performance, 5, 674-691.

Hasher, L., Stoltzfus, E. R., Zacks, R. T., \& Rypma, B. (1991). Age and 
inhibition. Journal of Experimental Psychology: Learning, Memory, \& Cognition, 17, 163-169.

Hasher, L., \& Zacks, R. T. (1988). Working memory, comprehension, and aging: A review and a new view. In G. H. Bower (Ed.), The psychology of learning and motivation (pp. 193-225). San Diego, CA: Academic Press.

Hillis, A. E., \& Caramazza, A. (1990). The effects of attentional deficits on reading and spelling. In A. Caramazza (Ed.), Cognitive neuropsychology and neurolinguistics: Advances in models of cognitive function and impairment (pp. 211-275). Hillsdale, NJ: Erlbaum.

Jared, D., McRae, K., \& Seidenberg, M. S. (1990). The basis of consistency effects in word naming. Journal of Memory and Language, 29, 687-715.

Katz, R. B. (1991). Limited retention of information in the graphemic buffer. Cortex, 27, 111-119.

Levine, D. N., Mani, R. B., \& Calvanio, R. (1988). Pure agraphia and Gerstmann's syndrome as a visuospatial-language dissociation: An experimental case study. Brain and Language, 35, 172-196.

Liss, J. M., Weismer, G., \& Rosenbek, J. C. (1990). Selected acoustic characteristics of speech production in very old males. Journal of Gerontology, 45, 35-45.

MacKay, D. G. (1987). The organization of perception and action: A theory for language and other cognitive skills. New York: SpringerVerlag.

MacKay, D. G. (1993). Slips of the pen, tongue, and typewriter: A contrastive analysis. In G. Blanken, J. Dittmann, H. Grimm, J. C. Marshall, \& C. W. Wallesch (Eds.), Linguistic disorders and pathologies: An international handbook (pp. 66-72). New York; de Gruyter.

MacKay, D. G., \& Abrams, L. (1996). Language, memory, and aging: Distributed deficits and the structure of new-versus-old connections. In J. E. Birren \& K. W. Schaie (Eds.), Handbook of the psychology of aging (4th ed., pp. 251-265). San Diego, CA: Academic Press.

MacKay, D. G., Abrams, L., \& Pedroza, M. J. (in press). Aging on the input versus output side: Theoretical implications of age-linked asymmetries between detecting versus retrieving orthographic information. Psychology and Aging.

MacKay, D. G., \& Burke, D. M. (1990). Cognition and aging: A theory of new learning and the use of old connections. In T. M. Hess (Ed.), Aging and cognition: Knowledge organization and utilization (pp. 213-263). Amsterdam: North-Holland.

Maylor, E. A. (1990). Recognizing and naming faces: Aging, memory retrieval and the tip of the tongue state. Journal of Gerontology: Psychological Sciences, 45, P215-P226.

McCrae, R. R., Arenberg, D., \& Costa, P. T. (1987). Declines in divergent thinking with age: Cross-sectional, longitudinal, and cross-sequential analyses. Psychology and Aging, 2, 130-137.

Mitchell, D. B. (1989). How many memory systems? Evidence from aging. Journal of Experimental Psychology; Learning. Memory, and Cognition, 15, 31-49.

Neils, J., Boller, F., Gerdeman, B., \& Cole, M. (1989). Descriptive writing abilities in Alzheimer's disease. Journal of Clinical and Experimental Neuropsychology, 11, 692-698.

Nicholas, M., Barth, C., Obler, L. K., Al, R., \& Albert, M. L. (1997). Naming in normal aging and dementia of the Alzheimer's type. In $\mathrm{H}$. Goodglass \& A. Wingfield (Eds.), Anomia: Neuroanatomical and cognitive correlates (pp. 166-188). San Diego, CA: Academic Press.

Nicholas, M., Obler, L., Albert, M., \& Goodglass, H. (1985). Lexical retrieval in healthy aging. Cortex, 21, 595-606.

Norback, P. G. (1974). The misspeller's dictionary. New York: Quadrangle/The New York Times Book Co.

Olson, A., \& Caramazza, A. (1994). Representation and connectionist models: The NETspell experience. In G. D. A. Brown \& N. C. Ellis (Eds.), Handbook of spelling: Theory, process, and intervention (pp. 337-363). New York: Wiley.

Parkin, A. J., \& Walter, B. M. (1992). Recollective experience, normal aging, and frontal dysfunction. Psychology \& Aging, 7, 290-298.

Plaut, D. C., McClelland, J. L., Seidenberg, M. S., \& Patterson, K. (1996). Understanding normal and impaired word reading: Computational principles in quasi-regular domains. Psychological Review, 103, 56-115.

Poon, L. W., \& Fozard, J. L. (1978). Speed of retrieval from long-term memory in relation to age, familiarity, and datedness of information. Journal of Gerontology, 33, 711-717.

Posteraro, L., Zinelli, P., \& Mazzucchi, A. (1988). Selective impairment of the graphemic buffer in acquired dysgraphia: A case study. Brain and Language, 35, 274-286.

Rastle, K. G., \& Burke, D. M. (1996). Priming the tip of the tongue: Effects of prior processing on word retrieval in young and older adults. Journal of Memory and Language, 35, 586-605.

Rastle, K. G., \& Coltheart, M. (1996, November). Serial and strategic effects in reading aloud. Paper presented at the 37th Annual Meeting of the Psychonomic Society, Chicago.

Salthouse, T. A. (1996). The processing-speed theory of adult age differences in cognition. Psychological Review, 103, 403-428.

Stadtlander, L. M. (1995). Age differences in orthographic and frequency neighborhoods. In P. A. Allen \& T. R. Bashore (Eds.), Age differences in word and language processing (pp. 72-86). Amsterdam: North-Holland.

Thomas, J. C., Fozard, J. L., \& Waugh, N. C. (1977) . Age-related differences in naming latency. American Journal of Psychology, 90, 499509.

Treiman, R. (1993). Beginning to spell: A study of first-grade children. New York: Oxford University Press.

Wing, A. M., \& Baddeley, A. (1980). Spelling errors in handwriting: A corpus and a distributional analysis. In U. Frith (Ed.), Cognitive processes in spelling (pp. 251-273). London: Academic Press.

Received December 1, 1997

Revision received May 18, 1998

Accepted May 20, 1998 